Article

\title{
A Framework for Effective Science Communication and Outreach Strategies and Dissemination of Research Findings for Marine Energy Projects
}

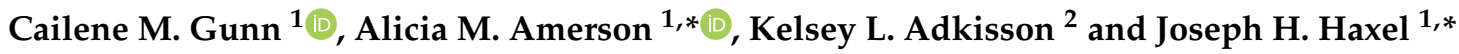 \\ 1 Pacific Northwest National Laboratory, Coastal Sciences Division, Sequim, WA 98382, USA; \\ cailene.gunn@pnnl.gov \\ 2 Pacific Northwest National Laboratory, Technical Communications, Richland, WA 99354, USA; \\ kelsey.adkisson@pnnl.gov \\ * Correspondence: alicia.amerson@pnnl.gov (A.M.A.); joseph.haxel@pnnl.gov (J.H.H.)
}

check for

updates

Citation: Gunn, C.M.; Amerson,

A.M.; Adkisson, K.L.; Haxel, J.H. A

Framework for Effective Science

Communication and Outreach

Strategies and Dissemination of

Research Findings for Marine Energy

Projects. J. Mar. Sci. Eng. 2022, 10, 130.

https://doi.org/10.3390/

jmse10020130

Academic Editor: José-Santos

López-Gutiérrez

Received: 16 December 2021

Accepted: 16 January 2022

Published: 19 January 2022

Publisher's Note: MDPI stays neutral with regard to jurisdictional claims in published maps and institutional affiliations.

Copyright: (c) 2022 by the authors. Licensee MDPI, Basel, Switzerland. This article is an open access article distributed under the terms and conditions of the Creative Commons Attribution (CC BY) license (https:// creativecommons.org/licenses/by/ $4.0 /)$.

\begin{abstract}
Marine energy is an emerging renewable energy industry with the potential to produce 2300 terawatt-hours per year from resources within the United States. As development and testing of marine energy devices advance, regulatory and permitting decision-makers are concerned about the uncertainty surrounding the potential environmental effects resulting from the introduction of these novel devices in coastal and riverine environments. The Triton Initiative researches and provides recommendations for environmental monitoring technologies and methods to inform industry stakeholders with the data necessary to permit the testing of marine energy systems. Effective dissemination of the research findings is essential for improving the accessibility of data to stakeholders who may use the results to inform policy decisions, yet few frameworks for conducting science communications for marine energy projects exist. In this paper, we present tools, channels, and tactics for developing a science communication framework for marine energy projects, or similar areas of study, using the Triton Initiative's pilot science communication program as a case study. By leveraging existing bodies of work in disciplines such as communications theory, marketing, public relations, and social science, the presented framework includes audience identification and analysis; channel development, including a website, blog, newsletter, social media, and webinars and presentations; and metrics for determining success. Outcomes from one year of Triton's case study are presented, including the most effective tactics and lessons learned.
\end{abstract}

Keywords: marine energy; environmental monitoring; science communication; communication strategy; communication framework

\section{Introduction}

In research, the dissemination and communication of scientific findings, use case experiences, and recommendations to stakeholders are a last, critical step that is often overlooked and arguably the most important. Traditionally, scientific methods and results are communicated through publication in peer-reviewed journals and written in technical language [1]. Limitations of this approach include inaccessible language that makes meaning unapproachable to audiences outside of the field of research, cost to access publications, and a format that does not communicate the importance of the research upfront [2,3]. Outreach, engagement, and marketing are not typically a component of traditional research or engineering processes. Yet, complementary science communications efforts are needed to better reach key audiences, improve access to results and findings, and amplify the impact of the research [3].

Science communication tailored to specific end-users is essential for the advancement of emerging clean-energy resources such as marine energy [1]. Uncertainty around the environmental effects of these technologies on marine species and habitats is a current 
barrier to permitting and deploying marine energy technology [4]. Permitting is contingent upon decision-makers having access to, and understanding, the environmental monitoring research and empirical data needed to evaluate uncertainty [5]. Additionally, social acceptance of renewable energy is found to be linked to stakeholder involvement and public perception, which can be addressed through science communication [6].

Science communication is an interdisciplinary, "boundary" field that leans on communication theory, such as marketing or public relations, to advance science and technology goals among key stakeholder groups [7]. Energy research tends to lack integration of social science concepts because of under-examined social dimensions and social science being viewed as secondary and peripheral, while in reality, the future of renewable energy requires the integration of both physical and social sciences to be realized [8]. Effective science communication advances research understanding, fosters trust in the scientific process, and builds stakeholder awareness of results or technology [5,9]. The current science communication literature for renewable energy projects details planning strategies and how communication efforts will be conducted. In the search to find how these strategies performed when implemented and what metrics were used to determine their success, little information was found about the results of these science communication efforts in the marine energy industry.

To fill this knowledge gap, the Triton Initiative (referred to as Triton herein) developed a science communication framework to engage audiences with research conducted in 2020 and 2021. Triton is a major U.S. Department of Energy Water Power Technologies Office project with a mission to reduce barriers to testing marine energy devices by developing and researching tools and methods for environmental monitoring by the marine energy community. The framework included a plan for communication, outreach, and engagement designed specifically to target key audiences in the marine energy industry. Additionally, based on communication best practices, metrics were created to measure overall performance, evaluate strategies, and tailor future communications to better reach key stakeholders. The fact that no single strategy, solution, audience, or message will encompass communication on complex science topics underscores the need for a suite of communication tactics and channels [10].

This paper presents tools, channels, and tactics for developing a science communication framework for marine energy projects, or similar areas of study, using Triton's science communication framework as a case study.

\section{Background}

Increasing national and global energy demands, coupled with the challenges associated with carbon emissions, require new and creative power generation technologies for renewable resources. Ocean power is an essential natural resource in the portfolio of renewable solutions [11]. Advancing new technologies that harness power from the marine environment propels the nation toward achieving reduced carbon, renewable energy goals. In particular, marine energy resources within the 50 U.S. states hold the technical power potential to produce 2300 terawatt-hours per year, or the equivalent of $57 \%$ of all of the electric power for utilities generated by those states in 2019 [12]. The energy generation potential from renewable ocean-based resources is significant and achievable, yet much of the novel technology required to harness marine energy is under development or has not been tested and demonstrated in open water [11].

Developing, testing, and validating technologies capable of converting and delivering power from the ocean to the electrical grid is a fundamental step toward realizing a renewable energy future. The emergence of new marine energy technologies and the continued improvements of existing devices require cycled testing and performance evaluation in open water coastal and tidal environments. However, regulatory and permitting decision-makers are concerned about the uncertain environmental effects of novel marine energy devices and the spatial overlap of these energetic environments with important habitats of marine species [4]. The Triton Initiative's Triton Field Trials (TFiT) activities 
described in this special issue provide recommendations and use cases for technologies and methods of environmental monitoring around marine energy device deployments. The recommendations include examples of monitoring technology applications at marine energy sites to inform industry developers, researchers, and the regulatory community by providing cost-efficient and meaningful data collection to assist future permitting and licensing of future marine energy projects.

While there is momentum and interest in meeting green energy targets, barriers to marine energy deployment persist. Device deployment hinges on permitting, which will only occur once uncertainty and potential risk associated with the environmental impacts of the devices is better understood. Research plays a central role in understanding that uncertainty. However, because of the nature of marine energy, communicating that uncertainty effectively means overcoming disconnects between science, policy, and communications.

Prior to 2021, the Triton project lacked clear avenues to connect to its user base. For four years, the project only conducted minor communications and outreach as part of specific technical work. Given the lack of avenues to connect with core audiences, along with the impetus to build awareness around marine energy research, Triton sought to (1) raise awareness of the purpose of Triton and the relevance of its research to target audiences, (2) cultivate relationships with key audiences that could help advance Triton's research and development goals, and (3) encourage engagement with audiences and tailor communication efforts.

To demonstrate the utility of a communications program, Triton updated the existing project website and piloted a Triton Stories blog to share stories, along with details about Triton's researchers and projects (Table A1) [13]. These stories were designed to educate, update, and establish an audience. The stories added a human element to the website-connecting technological advances in marine energy environmental monitoring to the researchers working on the topic. After publishing three Triton Stories over several months, there was an observed increase in website viewership (Figure A1). Other value-added propositions included the ability for management and funding sponsors to track Triton activities and connect the research to the team. Triton team members were able to share links among colleagues, which led to awareness among research audiences and to future collaborations and partnerships. The effort served as a proof of concept for developing a framework for a formal task dedicated to communication, outreach, and engagement, focusing on educating and connecting marine energy industry stakeholders to Triton's research.

Building from the proof of concept, Triton developed a more robust communications framework (Figure 1) designed to connect key audiences with Triton's research and establish communication goals to advance Triton's overall mission. The framework implementation included identifying key target audiences, selecting platforms that aligned with targeted stakeholders, and creating regular and engaging content to connect audiences with research. This framework concludes with preliminary results and outcomes from each of the communication strategies and activities implemented throughout the year, along with the lessons learned. 


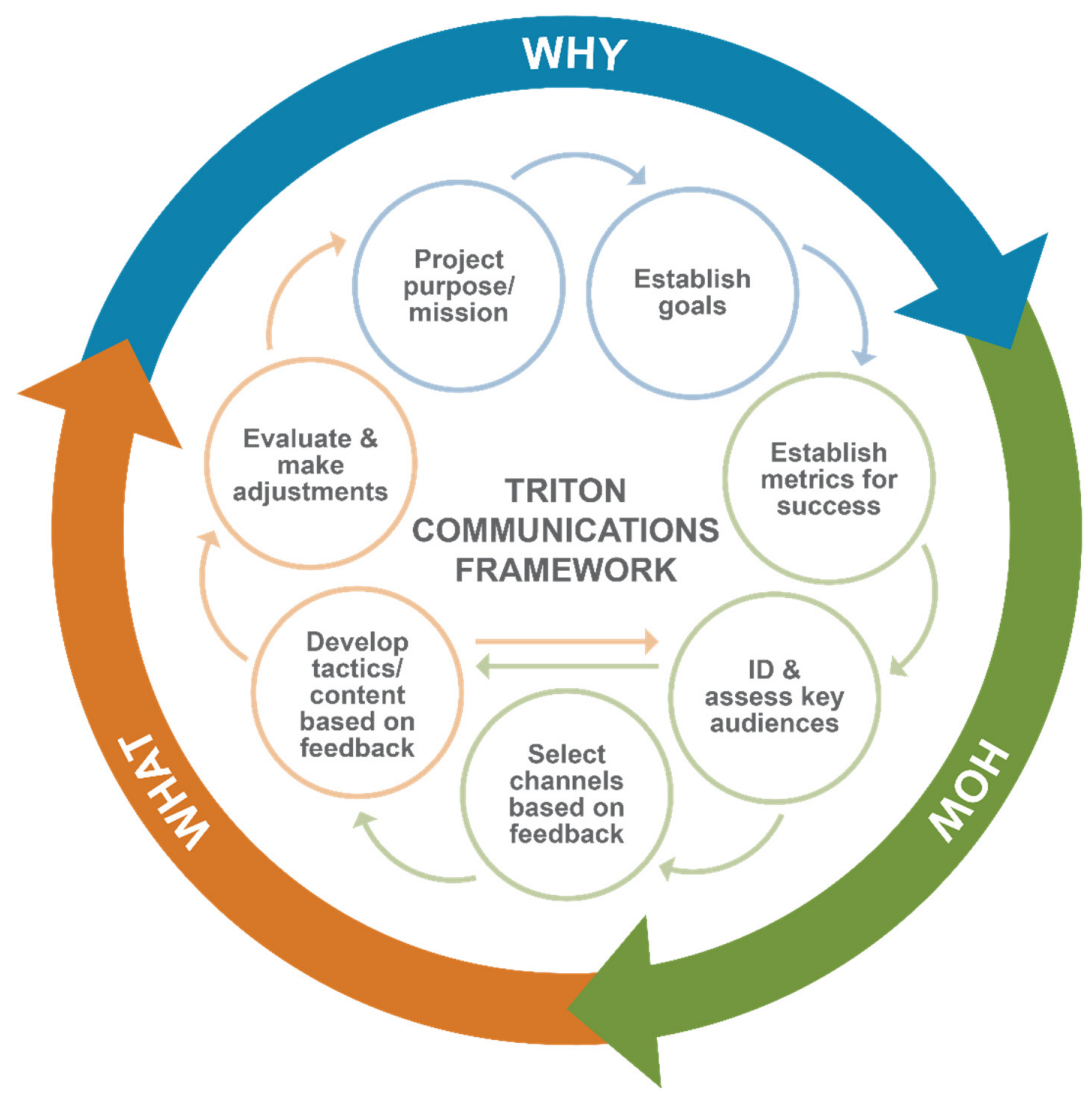

Figure 1. Triton communications framework for developing strategic communications content to support research project mission and communication goals. (Diagram by Stephanie King, Pacific Northwest National Laboratory.)

\section{Methods}

\subsection{Framework Development}

In developing a framework, Triton used the project mission and purpose as driving forces to establish the following communications goals:

- Increase awareness about marine energy and the environmental monitoring research being done to reduce barriers to permitting marine energy systems;

- Develop and refine tactics to inform stakeholders about Triton's research.

Once the goals were established, the Triton team determined metrics to measure success based on specific, prioritized audiences, along with the channels and content relevant to those audiences. The development of communications channels involved a general update of the website to improve information access and organization related to the diverse projects under Triton. Additionally, we leveraged existing social media channels used by Triton's parent organization, Pacific Northwest National Laboratory (PNNL), to reach broader audiences and further amplify content. Events such as podcasts, webinars, and conferences were also added to expand our audience and diversify our reach. We designed a newsletter that connected with a subscriber list monthly about Triton's research efforts. Lastly, the team provided consistent access to information about Triton's research and team through the monthly Triton Stories blog. These efforts were strategically outlined in a communication plan that established how associated activities would connect to target audiences.

Initial framework development involved identifying markers for success for each channel, which included metrics and baseline expectations for channels to be considered successful (pageviews, open rates, number of stories published, etc.). Results and notable successes were tracked throughout the year, delivered monthly to the sponsor, and reported 
in a year-end report. Year one (October 2020-September 2021) metrics data were then used as a baseline for future framework development.

\subsection{ID Key Audience}

One of the most important pieces of developing a communication strategy is prioritizing precise target audiences in relation to the overall goal and inviting them as participants in the science communication process [14]. The marine energy industry comprises vastly different audiences, many of which are interested in different aspects of research and prefer certain communication channels. Audiences that play a central role in advancing the marine energy industry include marine energy regulators and decision-makers, marine energy end-users such as local communities, research partners, marine energy developers, ocean advocacy groups, and others [6].

The Triton communications team mapped target audiences with support from a sister project, Ocean Energy Systems-Environmental, which focuses largely on data sharing with and outreach to marine energy stakeholders [15]. Additionally, outreach to partner organizations and strategic discussion with the project sponsor helped identify the target end-users of Triton products. Through this process, Triton's key audience groups identified included research partners, marine energy stakeholders, and general audiences (Table 1).

Table 1. Triton Initiative key audiences.

\begin{tabular}{cc}
\hline Audience Group & $\begin{array}{c}\text { Target Audience Members } \\
\text { Research partners }\end{array}$ \\
$\begin{array}{c}\text { Private sector members (e.g., technology and sensor } \\
\text { developers, subject matter experts), academia, state and } \\
\text { federal government agencies }\end{array}$ \\
\hline Marine energy & $\begin{array}{c}\text { Developers, regulators, policymakers, consultants, } \\
\text { marine energy end-users }\end{array}$ \\
General audiences & $\begin{array}{c}\text { Science-interested public, nonprofit organizations, coastal } \\
\text { citizens, ocean advocates, communities and industries with } \\
\text { strong ties to marine energy testing locations }\end{array}$ \\
\hline
\end{tabular}

Through an ocean science-specific conference workshop, Triton cultivated initial email connections with specific targeted audiences, including researchers in the environmental monitoring for marine energy space, and other key stakeholders in the industry connected to project research. This allowed key audiences to be reached using several tactics and channels, including emails, newsletters, surveys, or workshop invitations.

\section{Audience Analysis}

An audience analysis is a process used to identify and understand priority audiences, including their roles, knowledge about research topics, and interests. Online surveys are a way to engage key audiences and solicit feedback. As part of a virtual conference workshop that included regulators, developers, researchers, consultants, and marine energy stakeholders, Triton launched a 16-question SurveyMonkey survey (Appendix B). This qualitative survey sought input on recommendations through multiple-choice and open-ended questions designed to understand the respondents' roles within the marine energy industry, environmental monitoring needs within each role, and ideas about how to improve environmental monitoring practices. The survey was also widely disseminated through various channels including the website, newsletters, and through direct contact with workshop invitees. Responses were used at a programmatic level to improve recommendations, maximize product use, and guide the overarching communications strategy. 


\subsection{Platform Development}

\subsubsection{Website}

Websites are central information repositories and in the digital age, a web presence is often a foundational and essential building block for advancing a communication strategy. An online presence helps overcome the challenge of access to information in a way that is both cost-effective and accessible to nonscience audiences. The execution of communications activities and channels began with website updates and migrating the project website from a small, stand-alone website to a project page on PNNL's central platform, thereby increasing exposure and enabling the development of additional webpages. All of Triton project details, including research project descriptions, ways to work with the team, webinars, publications, blog posts, and research updates, were hosted on the new website [16]. The expansion and improvement of the website content was necessary for the development of all other communications activities designed to drive traffic to the web content.

The website was updated regularly to provide accurate, current, and transparent information, which can ultimately help build trust with audiences. Additionally, a lead generator was used to collect the emails of interested audiences for the monthly newsletter. Monthly and annual analytics from Google Analytics were reviewed, including pageviews, users, new users, and basic information about the platforms used to access the website and countries of origin. Coupled with an overarching strategy of driving outbound channels, such as social media, back to the website, this provided information about how users interacted with key information and showed connections to channels.

\subsubsection{Triton Stories Blog}

Blogs are a way to keep websites updated with new or current content, keep audiences engaged, and bolster the overall program mission. They also offer an opportunity to provide plain-language explanations of technical research or technology topics and introduce a human element to a science and technology-focused website.

The Triton Stories are a monthly blog comprising 1100- to 1800-word plain-language stories that feature Triton's research and researchers, and dive into an aspect of the program's mission (Table A1). The topics touch on career paths to science, research passions, and contributions to the project. Hosted on Triton's project website, Triton Stories link to relevant website pages and partner information. Each story was published at the beginning of each month, and disseminated through social media, the website, and internal and external newsletters disseminated to target audiences. Monthly pageviews were provided via Google Analytics for individual stories, and qualitative testimonials were collated as stories were published.

\subsubsection{Newsletter}

Newsletters provide a platform for delivering detailed project information and resources and engaging with self-selecting audiences [17]. Newsletter subscribers were collated through a subscription form promoted through direct outreach to stakeholders, social media posts, and a website lead generator. The form asked subscribers for their name, email, and affiliation, allowing subscribers to be categorized for audience composition tracking.

The Triton newsletter was disseminated to subscribers using HubSpot's subscription service. The newsletter was designed and launched within one month of initial planning. Each newsletter featured the month's Triton Story; information regarding fieldwork or tests conducted; a spotlight on a research project, a staff member or partner; a news section to feature upcoming events, publications, or other content; and a question prompt to engage with subscribers (Table A2). This format was strategically designed to appeal to the target audiences and provide opportunities to gather feedback. 


\subsubsection{Social Media}

Different audiences prefer to obtain information in a variety of ways, including informal, nontechnical channels such as social media. Social media provide a relatively low-cost opportunity to reach key stakeholders and further promote more high-investment efforts, such as videos or blogs. Triton established a social media presence on Instagram, LinkedIn, Twitter, and Facebook through PNNL's channels. Project-related content was posted regularly (bi-weekly to monthly) using SproutSocial social media scheduling software. Post content featured Triton's research, monthly Triton Stories, and engaged PNNL's audiences with the project mission and efforts, linking to website content. These posts were designed to have a consistent look and feel and used the Triton logo whenever possible as a distinguishing element, particularly on platforms with high post volumes.

Most social media platforms track data, which allows for the measurement of post performance and how audiences view or interact with information. The individual platforms use algorithms to rank content for their users, and the metrics reflect how well that content performs against each platform's algorithm. These algorithms change often, so the context of the datapoints becomes important. Engagement is an overarching category that represents how an audience interacts with content, and includes metrics such as likes, comments, and shares. Impressions and reach are also measured, indicating how many times a post shows up in a user's timeline and providing useful information about audience awareness. Using data compiled through SproutSocial, Triton posts were tracked monthly in terms of engagement and impressions, then aggregated annually to evaluate trends over time. In the first year of implementation, Triton averaged 2-3 Instagram posts per month, and 1-2 posts on Twitter, LinkedIn, and Facebook, all on PNNL's laboratory-wide platforms.

\subsubsection{Webinars and Presentations}

Webinars, workshops, and presentations were given by Triton researchers and the communications team as key outreach and engagement efforts to tailor messaging to specific, targeted audiences, and create opportunities for open discussion and feedback through surveys. These events were promoted via newsletter, website, and social media, and recorded videos were hosted on the project website as free, accessible resources.

The Triton team hosted a webinar on each of the TFiT stressors through an oceanscience conference titled "Collaboration for Marine Renewable Energy Environmental Monitoring Guidelines." This webinar provided background on stressor research and updates on project progress and facilitated a discussion about the marine energy industry's environmental monitoring needs. A post-webinar survey was created and disseminated through targeted email blasts to gather feedback about the webinar. The survey feedback was provided to task leads for consideration during the implementation of the TFiT and the writing of recommendations.

Webinars and presentations throughout the year created opportunities for the Triton team to provide project updates to diverse, targeted audiences and share information about upcoming events or content. Public, recorded webinars and presentations were posted to YouTube and the project website, and views were tracked.

\section{Results}

With recent advances in marine energy technology came growing interest in Triton's research results, specifically among nonscience audiences. In July 2020, Triton's initial pilot launch of three Triton Stories saw preliminary success in terms of increased website traffic, with spikes in pageviews corresponding to Triton Story publish dates (Figure A1). Based on this limited success, there was interest in comprehensively growing communications efforts in a more strategic way. Triton began building the communications framework, which grew to include audience survey work, website expansion, monthly science blogs, social media, and a newsletter.

Respondents $(n=20)$ for Triton's survey from the "Collaboration for Marine Renewable Energy Environmental Monitoring Guidelines" workshop comprised 30\% developers, 
$25 \%$ researchers, and $20 \%$ consultants, with the remainder comprising agency staff, industry members, or policy leads. This role composition revealed consultants as engaged participants, which were thereafter included as a target audience. In terms of end-users for Triton's mission, a quarter of the respondents had some role in environmental permitting and $40 \%$ were involved in some form of environmental impact assessment. While decision-makers were represented, $26 \%$ of the respondents were unfamiliar with wave energy devices and nearly half ( $54 \%$ ) were unfamiliar with tidal devices. In terms of the types of marine energy research topics conducted by Triton, the respondents were least familiar with electromagnetic fields (32\%), while over half were familiar with the effects of underwater noise $(58 \%)$, and $42 \%$ were familiar with changes in habitat related to marine energy device deployment. In response to a question regarding instrument needs for monitoring, one respondent replied: "it's the cost of such instrumentation and technology that needs to come down significantly," which informed research considerations where possible. For example, the call for cost-effective technology led the TFiT underwater noise research team to pursue low-cost hydrophone technologies for their field tests, a consideration that will continue to inform technology selection for future projects.

Other survey respondents articulated a need for better communication and dissemination of information among stakeholders. One developer said: "it seems permitting requirements and monitoring requirements differ by region and permitting body-knowing which types of monitoring we are most interested in as a marine energy developer is difficult without first having a clear idea of what monitoring will be required for future permitting," and a regulator added: "inform regulators! The more regulators understand the more pertinent the data requirements for permits will be." Overwhelmingly, respondents called for some form of standardization of environmental monitoring requirements and a way to share data with those who use them, reinforcing the need for Triton's role in the marine energy industry.

The lack of understanding of certain research areas guided the focus of the plainlanguage science blog topics and informational social media posts in an effort to make those topics more accessible. Additionally, qualitative audience feedback stated the need for the synthesis of science to support decision-making, enhanced information sharing, and the need for general communication of marine energy technology. This feedback was used to drive TFiT's recommendations and later inspired the development of a webinar series dedicated to communicating results to end-users.

Based on the survey results and to further enhance information sharing, Triton began to ramp up its online presence. Web content, which, if used effectively, is dynamic in nature, allowed for regular updating of scientific information through project summaries, science blogs, published resources, and information about the research team. Between April and August 2021, Triton's pageviews increased by $57 \%$, with the top pages being the home page, the Triton Stories blog landing page, and information about the research projects.

The Triton Stories blogs were consistently highly viewed pages, collectively accounting for more than $50 \%$ of the pageviews on the entire Triton website. The largest number of Triton Story views were during the month of publication, with continued views in subsequent months. Hyperlinking past stories in newsletter features and embedding them in other stories contributed to extended readership post publication, thereby extending the article lifecycle.

Aside from the website, channels such as social media increased the likelihood that a nontarget audience not foreseen during framework development might access information. By using PNNL's social media, the project increased exposure to technical and science-curious audiences on national laboratory channels that have inherently interested audiences. Blog views increased on days when social media posts were released. On average, LinkedIn tended to be the most successful platform in terms of promoting the Triton Stories blog, while Facebook tended to be the most effective for engagements. Of all four platforms, Twitter contributed the largest number of impressions, with LinkedIn following (Table 2). Notably, in April 2021, the U.S. Department of Energy's Twitter account 
retweeted Triton's newsletter announcement, encouraging the account's 790,000 followers to subscribe. This retweet led to 17,595 impressions and 12 new newsletter subscribers that day alone (Figure 2a).

Table 2. Summary of Triton social media metrics by platform from November 2020-September 2021.

\begin{tabular}{cccccc}
\hline $\begin{array}{c}\text { Social Media } \\
\text { Platform }\end{array}$ & $\begin{array}{c}\text { Number of } \\
\text { Posts }\end{array}$ & $\begin{array}{c}\text { Total } \\
\text { Impressions }\end{array}$ & $\begin{array}{c}\text { Average } \\
\text { Impressions/Post }\end{array}$ & $\begin{array}{c}\text { Total Triton Link } \\
\text { Clicks }\end{array}$ & $\begin{array}{c}\text { Total } \\
\text { Engagements }\end{array}$ \\
\hline Facebook & 17 & 21,559 & 1283 & 153 & 1006 \\
Instagram & 28 & 18,901 & 675 & ND $^{1}$ & 917 \\
LinkedIn & 17 & 38,508 & 2263 & 536 & 77 \\
Twitter & 16 & 43,100 & 2814 & 766 & 847 \\
Total & 78 & 122,068 & ND $^{1}$ & 3675 \\
\hline
\end{tabular}

${ }^{1}$ No data available.

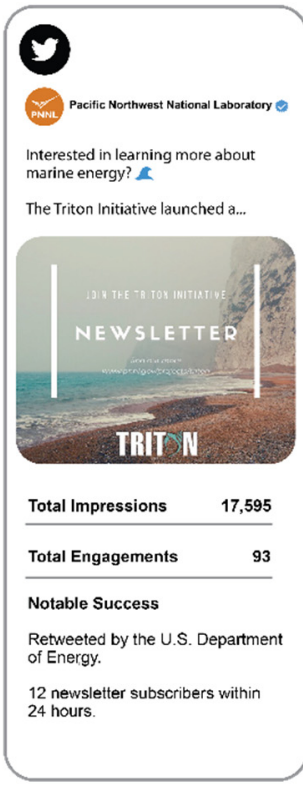

(a)

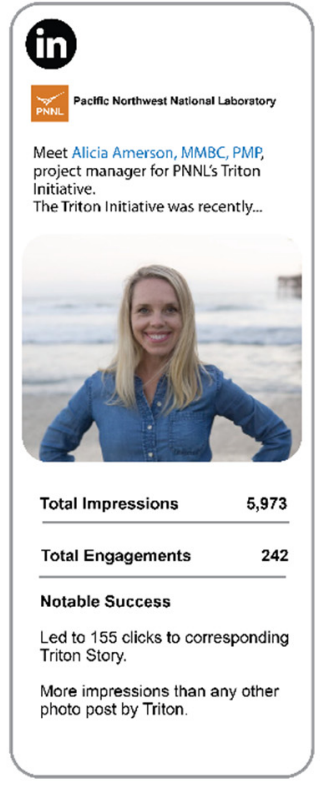

(b)

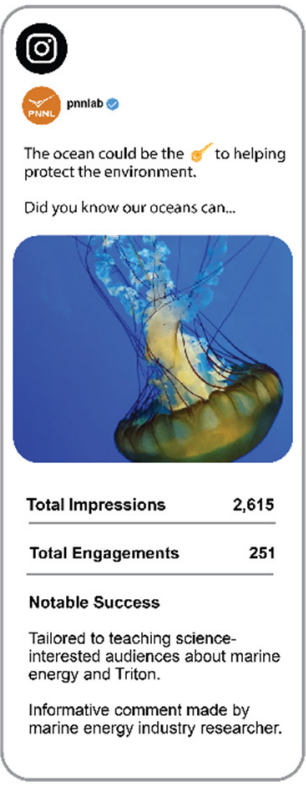

(c)

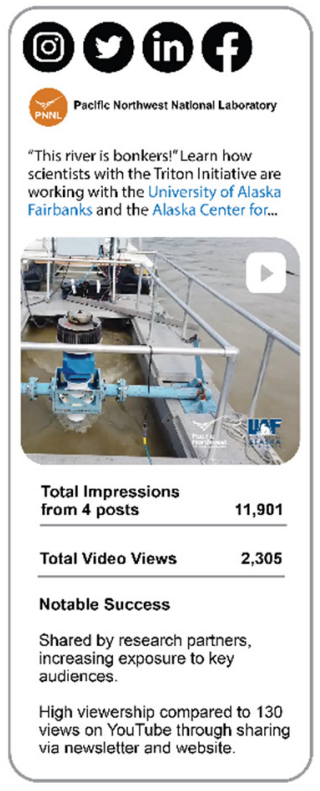

(d)

Figure 2. Examples of social media posts curated by Triton, including (a) a Twitter post promoting the Triton newsletter; (b) a LinkedIn post featuring a Triton team member and Triton Story; (c) an informational Instagram post about marine energy; and (d) a partner video highlighting TFiT field research shared on Instagram, Twitter, LinkedIn, and Facebook. Data compiled from each social media platform through SproutSocial.

With a promotional effort on social media, the addition of a signup link on the website, and regular promotion during conferences or presentations, the newsletter consistently grew from its launch in March 2021. The analysis of audiences subscribed to the Triton newsletter showed that the target audiences were reached, including $41 \%$ research partners/universities, 36\% marine energy stakeholders/developers, and 23\% general audiences. Email newsletter evaluation is typically measured through open rates (one per reader per email) and click-through rates (links within the newsletter text). Open and click-through rates vary widely by industry, with open rates for government organizations falling at around $20-25 \%$ on average, and a click-through rate of around 1-2\% [18]. Triton's newsletter had an average open rate of $50.5 \%$, compared to an average of $25.5 \%$ open rates for government newsletters. The click-through rate $(27.6 \%)$ for the Triton newsletter also exceeded the industry standard (3.9\%) [18]. Table 3 provides monthly subscriber, open rate and click-through rate data from all Triton newsletters published March 2021-September 
2021.The newsletter was an effective vehicle for sharing the Triton Stories blog with key audiences, and the release dates corresponded to spikes in website pageviews of the blog.

Table 3. Summary of Triton newsletter metrics by month from March 2021—September 2021.

\begin{tabular}{ccccccccc}
\hline Month & March & April & Special Issue & May & June & July & August & September \\
\hline Subscribers & 58 & 81 & 86 & 99 & 104 & 107 & 110 & 113 \\
Open Rate & $51.7 \%$ & $43.2 \%$ & $47.7 \%$ & $52.5 \%$ & $46.2 \%$ & $58.9 \%$ & $52.7 \%$ & $51.3 \%$ \\
Click-Through Rate & $40 \%$ & $34.3 \%$ & $19.5 \%$ & $23.1 \%$ & $33.3 \%$ & $20.6 \%$ & $27.6 \%$ & $22.4 \%$ \\
\hline
\end{tabular}

\section{Discussion}

\subsection{Developing a Project Goal and Why}

A project's mission and purpose should serve as a compass for communications. Most often, research projects start with a proposal that describes how the research will answer a challenging question, and why. The proposal process involves creating project goals and stating why the research is important to the funding agency or project sponsor. These early phase steps taken to identify meaning are also essential to informing communication efforts. Scope changes within a project can occur and a project's purpose must be amenable to change. As a project's purpose and mission evolve, so should its communications efforts.

By clearly understanding the purpose of Triton as a program and why the research matters, we were able to curate content and messaging for each of the channels that connects viewers to the project goals and why the research we do is important for supporting marine energy. The concise and clear purpose developed by the Triton team was published on the project website and used as the driving force for all communications content for viewers to better understand what we do, why, and most importantly, for whom [16]. In turn, this clear articulation of Triton's role provides opportunities to attract collaborations and research partnerships that can further support Triton's mission.

\subsection{How to Choose Types of Content and Platforms to Develop a Framework}

The most effective approach for communicating research depends on the goal of the communication [19]. This framework connects science and research with communications theory and practice, using a variety of tactics, some of which are less conventional within research settings, but are used widely within marketing and communications $[10,20]$. Determining what types of communications content to use should be fueled by the project mission and purpose, communications goals, target audiences, and the types of research results and their end-users.

For instance, one of Triton's primary research products from the TFiT research was a set of environmental monitoring recommendations published in this peer-reviewed journal special issue. A comprehensive communications campaign within the framework focused on building awareness of TFiT research topics, gathering feedback from marine energy industry stakeholders to inform recommendations, and providing project updates. As such, Triton invited its audiences to participate in the development of the recommendations for more than one year through surveys and other opportunities and engage with Triton's content via newsletter queries and presentations. Triton strategically developed communications content to support the TFiT campaign, including publishing newsletter spotlights, social media posts, and blogs about specific team members and research information related to TFiT. This multi-pronged approach to generating interest around a topic to increase exposure to information and feedback opportunities was used for all Triton research projects and products.

These targeted communications included a presentation on the TFiT project to the Marine Energy Council. This presentation resulted in several new industry contacts interested in partnering with Triton for their upcoming device demonstration and testing for environmental monitoring data collection. Other channels opened opportunities, including 
a marine energy test site inquiring about future collaboration through the project email box, and researchers pursuing career opportunities with the Triton team.

After the publication of the recommendations, the same channels-social media platforms, newsletter, website, and blog-are similarly used for dissemination purposes. A webinar designed to discuss recommendations with end-users will also be used for dissemination, along with a survey to quantify participants' understanding of results. Publication in open-access journals makes this public dissemination more effective, increasing access to results, enhancing the research cycle, and increasing exposure [1].

Implementing a framework and developing subsequent content can take significant resources, time, and money for research programs that are not well established or not connected as part of a larger organization. The steps in Triton's framework aid in choosing platforms and content regardless of the size of a communications program. The recommendation is to start small and build slowly. Starting small may include building a website that highlights the project's purpose and the team, launching a newsletter, adding a lead generator to the website to collect the emails of those who subscribe to the newsletter, and curating content for one social media platform. It may take months to a year to plan and build these foundational communication components. For example, Triton communications started with an existing stand-alone website and a few blog stories. Over the course of a few months, as the communication program was developed, the website was updated and more stories were published and highlighted on PNNL's Instagram platform. Triton gained momentum, expanding to other PNNL social media platforms and generating enough content to host a monthly newsletter. Every three to six months, a new product or opportunity to grow the audience was identified and new content was developed to test on the existing platforms. Given the breadth of the target audiences identified for Triton's research results and products, the use of diverse tactics was necessary to reach each target.

A valuable effort in determining what specific platforms to start with involves investigating the platforms most suitable for your project's content and its goals, as well as the social networks most used by your target audience. Academic audiences and experts within technical domains represent future partnerships, collaboration, and recruitment opportunities. Traditional communication channels such as journal publications and conferences play a role targeting traditional academic audiences. That said, nontraditional channels such as social media, specifically Twitter, have an active academic presence, serve as opportunities to promote research, and have been shown to provide a valuable contribution to scientific publishing [21]. The past decade has seen a swift rise in social media usage, although these platforms are arguably still underused by some academic communities [22].

Each social media platform has strengths that can be used advantageously. Twitter has served as a preferred social network platform to teach and engage people about the importance of science, disseminating scientific publications, and promoting project content [21,23]. The Twitter hashtag \#scientistswhoselfie has more than 25,663 posts, and research found that in a scientist selfies study, participants considered scientists posting selfies to be warmer, more trustworthy, and no less competent than scientists posting science-only photos [24]. Based on this result, we amplified Triton researchers in a nontraditional way and featured images where scientists were smiling and seemed more approachable (Figure $2 \mathrm{~b}$ ). Instagram is a very visual platform and supports the building of high-level awareness of science topics (Figure 2c) [25]. Facebook allows flexibility in the types of sharable content, with the ability to share public or private posts that include links, photos, and videos, and LinkedIn is most successful for building professional relationships, including networking and publicizing career opportunities [26]. Figure 2 provides examples of successes on multiple social media platforms, and demonstrates that while data can be inconsistent, social media are versatile and each platform provides opportunities for exposure and engagement to a variety of target audiences. We found sharing a piece of photo or video content on multiple social media platforms allowed the benefits of each platform to be leveraged and following to be reached. A partner video highlighting TFiT field research shared directly on all social media platforms resulted in 2305 total direct video 
views on social media compared to 130 views on YouTube achieved through promotion via the newsletter and website alone (Figure 2d).

Seeking inspiration from an industry leader or organization on their various social media platforms could be a valuable first step to incorporating social networks into a communication framework. Following and connecting with industry partners on social media and sharing their content is a key effort in developing a presence within social media communities. Using hashtags strategically, sharing content that engages with audiences through quizzes or polls, and content that provides behind-the-scenes perspectives of science can all help build engaged followings.

Compared to social media, blogs are more long-form development efforts that require dedication and consistency. While they require greater initial investments of time than social media, blog content can be widely disseminated using such platforms, linked via search engine terms, and provide an informative resource that remains accessible for years [27]. Newsletters have similar long-term benefits to blogs, but are less time-intensive and may include less technical detail.

\subsection{Lessons Learned and Successful Strategies}

An effective communications strategy includes feedback loops to tailor communication efforts, which inherently makes its implementation an adaptive and iterative process where metrics and feedback inform future efforts [2]. While strategic and thoughtful planning is critical, it is expected that tactics will be adjusted as the communication efforts mature, and there will likely be unanticipated challenges, new strategies, or audiences to consider. Furthermore, trying new efforts that were not initially planned for might bring success in terms of better reaching a key audience and goal.

In an era of competing attention spans online, leveraging research partners, sponsors, or others who play a role in the research effort can further amplify social media posts to audiences that are specifically interested. For example, two of the top-performing social media posts each featured a Triton staff member, which were substantially reshared within Triton's research team, elevating the overall metric performance of each post. This highlights the value of developing an internal sharing strategy to increase exposure to additional audiences and supporters. Other high-performing posts included one-minute videos co-created with research partners that featured compelling field footage that was strategically cross-tagged among collaborators (Figure 2d). In recent years, with growing interest in science communication and the rise of social media to promote research, different efforts have been made to heighten the visibility of the diversity of researchers and careers within science fields in an effort to cultivate trust, awareness, and opportunities in the science, technology, engineering, and mathematics fields [24].

At the core of communications is compelling content, which is specific to audience interests, communicated in an understandable way and shared via channels that align with the target audiences. Compelling content that is specifically of interest to target audiences will enhance overall success. For example, sharing a text alone is not going to attract the same degree of engagement as adding a compelling image or video would [28]. Furthermore, overly technical information can fail on platforms like social media because it is not easily digestible in plain language with a visual component.

\subsection{Metrics for Measuring Success}

One of the most challenging steps in any outreach or engagement effort is measuring success. This is because there is no single definition, metric, or method that encapsulates overall communication effectiveness. Evaluation can be quantitative or qualitative in terms of measuring the steps that advance the overall goal. The key piece of assessing the audience involves gathering feedback on communications to obtain the sense of the overall profile of a project. This enables a direct assessment, indicates whether goals have been achieved, and can help guide the decision to reinforce or rework communication tactics. Incorporating ways to quantifiably measure effectiveness ensures that information 
about priority audiences gets factored into the overall strategy, rather than relying on intuition alone.

In practice, evaluating communication effectiveness relies heavily on survey results, among other tactics [29]. Triton's launch of the post-workshop informative survey gathered valuable feedback used to inform environmental monitoring technology field trials and subsequent industry recommendations for the use of these technologies. The survey created an opportunity to gather key information early on about audiences, including their roles in the industry, understanding of specific project-related topics, and areas for development in the marine energy environmental monitoring technology space. Additionally, the survey allowed the Triton team to gauge interest in future Triton-related content, serving as the basis for newsletter subscribers. More robust survey work is needed to quantify understanding and change in perception as a result of communications efforts.

If part of the overall strategy, the number of views on a webpage, social media metrics, click-through rates, or open rates in newsletters provide a certain level of information about how people view or access information. Patterns in data indicating connections among content types can also lead to useful insight into the use of channels as drivers to other content. The success of the tactics and communications efforts implemented through Triton's communications framework were largely assessed through audience composition, connections among content, and feedback from those engaging with content. The metrics for all platforms, audiences, and content connections were tracked monthly and comprehensively evaluated on an annual basis. Because audiences were generally self-selecting, such as through newsletter signups or engagement with science-oriented social media accounts, leveraging those channels automatically cultivates an interested user base. Using surveys and open feedback channels as pathways to learn about those self-selecting audiences and how they interact with content provides insight on effectiveor ineffective-tactics. Embedded within each method for measuring success is a valuable opportunity to assess the effectiveness of tactics relative to reaching key audiences and supporting the project goals and adjust accordingly.

Due to the nature of this framework as a pilot, the overall results establish a baseline for future measurement of growth and effectiveness. Within the scope of work, success was measured through monitoring audience composition and proportion alignment with key audiences. Additionally, careful tracking of how communications efforts positively influence research decisions as an indicator of success was found to be valuable. Future metrics of success will be built from the year one baseline and will enable more vigorous analysis and survey work to quantify impact.

\subsection{Partnership Development}

Most funding sponsors like to see project collaboration that includes multiple research partners. Triton is a project founded on technology development partnerships and collaborations with marine energy test site developers. The diversity of partnerships is key in a project, especially when working with scientific research. Leveraging the communications teams or efforts within a partnership can be beneficial for growing an audience and developing compelling content.

Throughout the implementation of Triton's communications framework, the team strategically connected with communications professionals at partner organizations to collaborate on the creation of communications content and provide exposure to one another's audiences. This approach provided opportunities to collaborate on written pieces, newsletter highlights, social media campaigns, and other creative communications efforts. This co-developed content was cross promoted across several social media platforms by each institution and strategically shared among researchers themselves. These partnerships also enabled projects to reciprocally leverage resources and capabilities to collect video and photo content for fieldwork to limit the travel and costs associated with capturing and generating content. If possible, partnership development efforts should be pursued early on in framework development to maximize mutually beneficial opportunities. 
Triton found that partnerships with communications professionals associated with research partners resulted in key successes for the communications task. During out-of-state fieldwork campaigns, local partners were able to provide onsite video and photography because of the reduced travel during the COVID-19 pandemic. Content co-developed through this partnership was cross promoted in newsletters and social media, and videos were hosted on YouTube and posted on the project website. The highlighting of offsite research fostered interest in Triton's fieldwork and increased mutual exposure to partner audiences. Co-developed videos derived from these partnerships were among the best performing posts on social media in the first year (Figure 2d).

\section{Conclusions}

Through the Triton communications framework, we seek to leverage existing bodies of work in disciplines such as communications theory, marketing, public relations, and social sciences to improve our science communication strategy. Triton is a large research program that has demonstrated the benefits of such a communications framework to engage key stakeholders, share research, and advance the project mission. This framework will continue to serve Triton as additional research on marine energy and environmental monitoring takes place over the next three years and beyond. In making the Triton communications framework's preliminary results and outcomes publicly available, we hope to provide tools for marine energy research projects, and projects conducting similar research, seeking to increase science communications.

The current marine energy audience is small in comparison to other renewable energy sources, such as offshore wind and solar. We propose that those interested in outreach and engagement for marine energy topics come together for collaboration and partnership. As other marine energy-related projects develop, it will be useful to share science communication strategies and frameworks. The data collected and lessons learned are valuable for promoting marine energy as an emerging new energy source that many communities may know little about or have limited access to information about. Through partnerships communicating the benefits of harnessing ocean energy, and by honing the ways research informs the regulatory decision-making process, science communications can meaningfully contribute to the advancement of the marine energy industry.

Author Contributions: Conceptualization, A.M.A., C.M.G. and J.H.H.; methodology, C.M.G., A.M.A. and K.L.A.; data collection, C.M.G. and K.L.A.; formal analysis, C.M.G.; data curation, C.M.G. and K.L.A.; writing—original draft preparation, C.M.G., A.M.A., J.H.H. and K.L.A.; writing-review and editing, C.M.G., A.M.A., K.L.A. and J.H.H.; project administration, A.M.A. and J.H.H.; funding acquisition, A.M.A., J.H.H. and C.M.G. All authors have read and agreed to the published version of the manuscript.

Funding: This research was funded by the United States Department of Energy Water Power Technologies Office under contract DE-AC05-76RL01830 with Pacific Northwest National Laboratory.

Institutional Review Board Statement: Not applicable.

Informed Consent Statement: Not applicable.

Data Availability Statement: Not applicable.

Acknowledgments: We thank our funding sponsor, Samantha Eaves, for supporting each step in developing a science communication framework. We also acknowledge the time she has provided to review the blog, newsletter, and website content. Shannon Bates has been key for Triton's communication development within PNNL; without her expertise, the program would not have grown as quickly as it has over the past year. TJ Heibel helped develop the initial communication program proposal to pitch to DOE; without his support at PNNL, this program would not exist-thank you, TJ, for believing in us. Mac Jaehnart has supported the creative efforts of Triton and allowed us to try new things on PNNL platforms; we appreciate the opportunity to explore. The enthusiasm of and ease of working with the University of Alaska, Fairbanks' Alaska Center for Energy and Power communication department, skyrocketed Triton's collision risk research; their being onsite to collect 
and produce an incredible video highlights our partnership, the research, and the researchers. The University of New Hampshire (UNH) communications department provided incredible footage of the Triton and UNH teams working together at the Living Bridge.

Conflicts of Interest: The authors declare no conflict of interest.

\section{Appendix A. Triton Stories Website Trends, Links to Triton Stories and Newsletter Issues}

Table A1. Triton Stories published from July 2020-September 2021, including links.

\begin{tabular}{ccc}
\hline Triton Story Title & Month Published & Link \\
\hline $\begin{array}{c}\text { Envisioning a Future with Marine Energy: } \\
\text { How Predictive Modeling Informs Decision } \\
\text { Making with Kate Buenau }\end{array}$ & July 2020 & //www.pnnl.gov/publications/envisioning- \\
future-marine-energy-how-predictive- \\
modeling-informs-decision-making-kate
\end{tabular}

Diving into Marine Renewable Energy Research with John Vavrinec

\section{Understanding Changes in Ocean Habitats to \\ Remove Barriers to Marine Renewable}

Energy Deployment with Lenaig Hemery

How to Measure the Invisible: Quantifying

Electromagnetic Fields with Molly Grear

Do Fish Swim Around or Through Energy

Devices in the Water? Understanding

Collision Risk Associated with Marine

Energy Devices with Garrett Staines

Creating Ears Under Water: Researching the

Effects of Underwater Noise with Joe Haxel

Bringing Triton's Vision to Life: Project Management with Alicia Amerson

September 2020

October 2020

November 2020

January 2021

February 2021

Safety First! How Triton Conducts Field

Operations Safely with Sue Southard

March 2021

April 2021

Building the Triton Initiative with Meg Pinza

Making Waves for Marine Energy: Triton from the Water Power Technologies Office Perspective with Samantha Eaves

Triton's Genesis: Celebrating World Oceans Month with Genevra Harker-Klimeš

Science Isn't Complete Unless It's Well Communicated: Sharing

Triton's Research with Cailene Gunn

Advancing Triton: Ocean-Based Climate

Solutions and Marine Advocacy with Simon Geerlofs

August 2021

June 2021

July 2021

May 2021

Teamwork Makes the Dream Work: Triton's Support of DOE-Funded Technology Projects

September 2021 https:

//www.pnnl.gov/publications/diving-marinerenewable-energy-research-john-vavrinec

https:/ / www.pnnl.gov/publications / understanding-changes-ocean-habitats-removebarriers-marine-renewable-energy

https:/ / www.pnnl.gov/publications/howmeasure-invisible-quantifying-electromagneticfields-molly-grear

https: / / www.pnnl.gov/publications/do-fishswim-around-or-through-energy-deviceswater-understanding-collision-risk

https: / / www.pnnl.gov/ publications / creatingears-under-water-researching-effectsunderwater-noise-joe-haxel

https:/ / www.pnnl.gov/publications/bringingtritons-vision-life-project-management-aliciaamerson

https:/ / www.pnnl.gov/publications/safetyfirst-how-triton-conducts-field-operationssafely-sue-southard

https:/ / www.pnnl.gov/publications/buildingtriton-initiative-meg-pinza

https://www.pnnl.gov/publications/makingwaves-marine-energy-triton-water-powertechnologies-office-perspective-samantha

https://www.pnnl.gov/publications/tritonsgenesis-celebrating-world-oceans-monthgenevra-harker-klimes

https://www.pnnl.gov/publications/scienceisnt-complete-unless-its-well-communicatedsharing-tritons-research-cailene

https:/ / www.pnnl.gov/publications / advancing-triton-ocean-based-climatesolutions-and-marine-advocacy-simon-geerlofs

https:/ / www.pnnl.gov/publications / eamwork-makes-dream-work-tritons-supportdoe-funded-technology-projects 


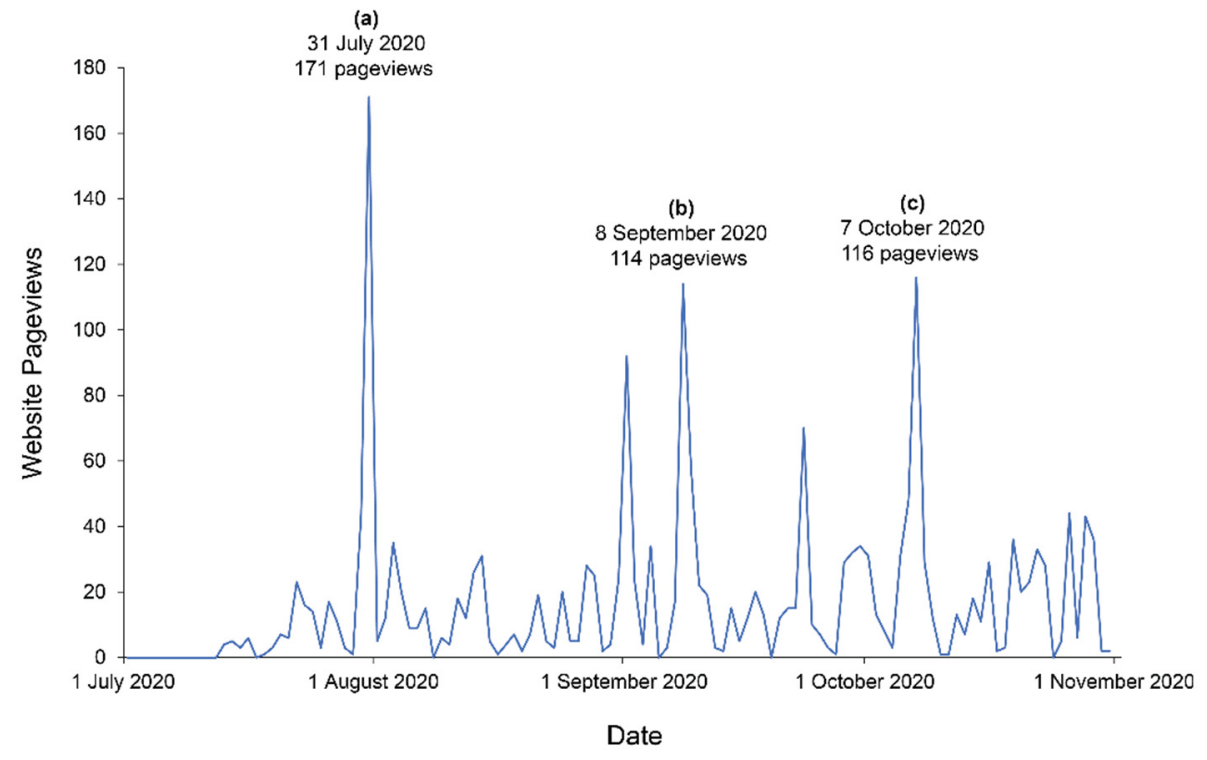

Figure A1. Example of Triton Stories blog publish dates corresponding to spikes in website pageviews from 1 July 2020 to 31 October 2020, including (a) predictive modeling Triton Story, published 31 July 2020, 171 pageviews; (b) research diving Triton Story, published 8 September 2020, 114 pageviews; and (c) changes in habitat research Triton Story, published 7 October 2020, 116 pageviews. Data from Google Analytics.

Table A2. Triton newsletter issues published from March 2021-September 2021, including links.

\begin{tabular}{|c|c|c|}
\hline Issue Month & Subjects & Link \\
\hline March 2021 & $\begin{array}{l}\text { Triton Stories on Alicia Amerson; Field Testing with Nolann } \\
\text { Williams; and BioSonics Perimeter Detector }\end{array}$ & https://bit.ly/3Fq8xEg \\
\hline April 2021 & $\begin{array}{l}\text { Triton Stories on Sue Southard; Field Testing with TFiT's } \\
\text { Change in Habitat Team; and Triton Celebrates Earth Day }\end{array}$ & https://bit.ly/3KaHOiv \\
\hline April 2021 & $\begin{array}{c}\text { International Conference on Ocean Energy Special Issue: } \\
\text { Kate Buenau's Poster on Models for Environmental } \\
\text { Monitoring; Triton Stories on Meg Pinza; and Alicia } \\
\text { Amerson Presents Public Seminar on Triton }\end{array}$ & https://bit.ly/33aX6TW \\
\hline May 2021 & $\begin{array}{l}\text { Triton: Samantha Eaves Featured in Triton Stories; Prepping } \\
\text { for Field Work; Rare Fish Found at MCRL; Triton News; and } \\
\text { Triton's Cailene Gunn }\end{array}$ & https://bit.ly/3qoEZ5B \\
\hline June 2021 & $\begin{array}{c}\text { Triton Stories on Genevra Harker-Klimeš; Collision Risk } \\
\text { Fieldwork; MCRL Field Tests; and Celebrating World } \\
\text { Oceans Month }\end{array}$ & https://bit.ly/33vRiUD \\
\hline July 2021 & $\begin{array}{l}\text { Triton Stories on Cailene Gunn; Collision Risk Fieldwork; } \\
\text { EMF Field Tests; and Welcoming Christa Hvidsten }\end{array}$ & https://bit.ly/34JxKN3 \\
\hline August 2021 & $\begin{array}{c}\text { Triton Stories on Simon Geerlofs; In the Field at the Living } \\
\text { Bridge; Spotlight on Christa Hvidsten; and Collision Risk } \\
\text { Nutshell Video }\end{array}$ & https://bit.ly/3KcA4N2 \\
\hline September 2021 & $\begin{array}{l}\text { Triton: Triton Stories on FOA projects; Fieldwork at MCRL; } \\
\text { Spotlight on BioSonics; Session at Ocean Sciences Meeting } \\
\text { 2022; and Olympic Peninsula Audubon Society supports } \\
\text { Triton's bird observations }\end{array}$ & https://bit.ly/3npmNXJ \\
\hline
\end{tabular}




\section{Appendix B. Triton Field Trials SurveyMonkey Survey Questions}

Question 1: What is your role within the marine renewable energy (MRE) community? (Checkbox)

- Regulator

- Developer

- Legislator

- Researcher

- $\quad$ Other (please specify)

Question 2: What is your familiarity or past experience working with the environmental stressors related to marine renewable energy? (Checkbox)

- Collision risk

- Changes in habitat

- Electromagnetic fields

- Underwater noise

- Tidal devices

- Wave devices

Question 3: What is your level of experience within the MRE industry? (Scaled: 1-have not heard of MRE to 5-my primary role is in MRE)

Question 4: What is your level of experience with MRE environmental monitoring? (Scaled: 1 -no experience to 5-experienced. If experienced, what part of environmental monitoring efforts are you involved with?)

Question 5: What is your level of experience with MRE permitting process? (Scaled: 1 -no experience to 5 - experienced. If experienced, what part of the permitting process are you involved with?)

Question 6: Do you have experience developing or implementing impact assessments and environmental monitoring programs for other ocean energy industries? (Checkbox)

- No

- Yes (please specify)

Question 7: Which existing regulatory requirements direct or inform the way you manage or permit MRE projects? (Checkbox)

- Magnuson-Stevens Fisheries Conservation and Management Act

- Marine Mammal Protection Act

- National Environmental Policy Act

- $\quad$ Species Monitoring Plans

- Threatened and Endangered Species Act

- $\quad$ Other (please specify)

Question 8: What type of environmental data is needed to fulfill the permit requirements? (Comment box)

Question 9: What instrumentation or technology is needed to collect the environmental data to fulfill requirements? (Comment box)

Question 10: What, if any, environmental monitoring challenges do you face in your role? For these challenges, please share if have you implemented any solutions. (Comment box)

Question 11: What, if any, permitting challenges do you face in your role? For these challenges, please share if have you implemented any solutions. (Comment box)

Question 12: Please share any other challenges you have faced, outside of monitoring and permitting, and include any solutions you have implemented. (Comment box)

Question 13: In your opinion, what are the next steps necessary for environmental monitoring and permitting in the MRE industry to progress in U.S. waters? (Comment box)

Question 14: Do you plan to attend the OCEANS conference and the workshop adjoining the conference? (Checkbox) 
- I plan to attend the conference and the workshop

- I plan to attend the conference only

- I do not plan to attend the conference or the workshop

Question 15: Would you be willing to participate in and/or contribute to future webinars regarding the creation of MRE guidelines for environmental monitoring? (Checkbox)

- No, not at this time.

- Yes, I'd like to participate (please provide name and email).

Question 16: Is there anything else you would like to share regarding MRE environmental monitoring, permitting, or technology development? (Comment box)

\section{References}

1. Mea, M.; Newton, A.; Uyarra, M.C.; Alonso, C.; Borja, A. From Science to Policy and Society: Enhancing the Effectiveness of Communication. Front. Mar. Sci. 2016, 3, 168. [CrossRef]

2. Weber, J.R.; Schell Word, C. The Communication Process as Evaluative Context: What Do Nonscientists Hear When Scientists Speak? Scientists and nonscientists benefit by recognizing that attempts at mutual influence, multiple frames of reference, and "objective" information in science communication are not neutral but evaluated with other social influences. BioScience 2001, 51, 487-495.

3. Shanley, P.; López, C. Out of the Loop: Why Research Rarely Reaches Policy Makers and the Public and What Can be Done. Biotropica 2009, 41, 535-544. [CrossRef]

4. Copping, A.; Hemery, L.; Overhus, D.; Garavelli, L.; Freeman, M.; Whiting, J.; Gorton, A.; Farr, H.; Rose, D.; Tugade, L. Potential Environmental Effects of Marine Renewable Energy Development-The State of the Science. J. Mar. Sci. Eng. 2020, 8, 879. [CrossRef]

5. Fischhoff, B. The sciences of science communication. Proc. Natl. Acad. Sci. USA 2013, 110, 14033-14039. [CrossRef]

6. Bonar, P.A.; Bryden, I.; Borthwick, A.G. Social and ecological impacts of marine energy development. Renew. Sustain. Energy Rev. 2015, 47, 486-495. [CrossRef]

7. Burns, T.W.; O'Connor, D.J.; Stocklmayer, S.M. Science Communication: A Contemporary Definition. Public Underst. Sci. 2003, 12, 183-202. [CrossRef]

8. Sovacool, B.; Ryan, S.; Stern, P.; Janda, K.; Rochlin, G.; Spreng, D.; Pasqualetti, M.; Wilhite, H.; Lutzenhiser, L. Integrating social science in energy research. Energy Res. Soc. Sci. 2015, 6, 95-99. [CrossRef]

9. Cash, D.W.; Clark, W.C.; Alcock, F.; Dickson, N.M.; Eckley, N.; Guston, D.H.; Jäger, J.; Mitchell, R.B. Knowledge systems for sustainable development. Proc. Natl. Acad. Sci. USA 2003, 100, 8086-8091. [CrossRef] [PubMed]

10. Ballantyne, A.G. Climate change communication: What can we learn from communication theory? Wiley Interdiscip. Rev. Clim. Chang. 2016, 7, 329-344. [CrossRef]

11. Melo, A.B.; Jeffrey, H. Ocean Energy Systems Annual Report: An Overview of Ocean Energy Activities in 2018; The Executive Committee of Ocean Energy Systems: Lisbon, Portugal, 2018.

12. Kilcher, L.; Fogarty, M.; Lawson, M. Marine Energy in the United States: An Overview of Opportunities; Office of Energy Efficiency \& Renewable Energy: Washington, DC, USA, 2021. [CrossRef]

13. Triton Stories Blog. Available online: https://www.pnnl.gov/projects/triton/stories (accessed on 13 January 2022).

14. Rogers, C.L. Making the audience a key participant in the science communication process. Sci. Eng. Ethic 2000, 6, 553-557. [CrossRef] [PubMed]

15. About OES-Environmental. Available online: https://tethys.pnnl.gov/about-oes-environmental (accessed on 13 January 2022).

16. Triton Initiative Website. Available online: https://www.pnnl.gov/projects/triton (accessed on 13 January 2022).

17. Flora, J.A.; Maibach, E.W.; Maccoby, N. The role of media across four levels of health promotion intervention. Annu. Rev. Public Health 1989, 10, 181-201. [CrossRef] [PubMed]

18. Chaffey, D. How Do You Compare? 2021 Average Email Open Rates, Clickthrough Rates, and Marketing Statistics Compilation. Available online: https:/ / www.smartinsights.com/email-marketing/email-communications-strategy/statistics-sources-foremail-marketing/ (accessed on 5 December 2021).

19. National Academies of Sciences, E. ; Medicine. Communicating Science Effectively: A Research Agenda; National Academies Press: Washington, DC, USA, 2017.

20. Wright, A.J.; Veríssimo, D.; Pilfold, K.; Parsons, E.; Ventre, K.; Cousins, J.; Jefferson, R.; Koldewey, H.; Llewellyn, F.; McKinley, E. Competitive outreach in the 21st century: Why we need conservation marketing. Ocean Coast. Manag. 2015, 115, 41-48. [CrossRef]

21. Darling, E.; Shiffman, D.; Côté, I.; Drew, J.; Côté, I. The role of Twitter in the life cycle of a scientific publication. Ideas Ecol. Evol. 2013, 6, 32-43. [CrossRef]

22. Jordan, K.; Weller, M. Academics and Social Networking Sites: Benefits, Problems and Tensions in Professional Engagement with Online Networking. J. Interact. Media Educ. 2018, 2018, 1-9. [CrossRef]

23. López-Goñi, I.; Sánchez-Angulo, M. Social networks as a tool for science communication and public engagement: Focus on Twitter. FEMS Microbiol. Lett. 2018, 365, fnx246. [CrossRef] 
24. Jarreau, P.B.; Cancellare, I.A.; Carmichael, B.J.; Porter, L.; Toker, D.; Yammine, S.Z. Using selfies to challenge public stereotypes of scientists. PLoS ONE 2019, 14, e0216625. [CrossRef]

25. Auxier, V.; Anderson, M. Social Media Use in 2021: A Majority of Americans Say They Use YouTube and Facebook, While Use of Instagram, Snapchat and TikTok Is Especially Common Among Adults under 30. Available online: https://www.pewresearch. org/internet/2021/04/07/social-media-use-in-2021/ (accessed on 5 December 2021).

26. Lévy, J. Social media for scientists. Nat. Cell Biol. 2018, 20, 1329.

27. Bik, H.M.; Goldstein, M. An Introduction to Social Media for Scientists. PLoS Biol. 2013, 11, e1001535. [CrossRef] [PubMed]

28. Kearns, C.; Eathorne, A.; Semprini, A.; Braithwaite, I.; Beasley, R. Public engagement with clinical research on social media; which visual medium works best? A 5-year retrospective analysis. J. Vis. Commun. Med. 2021, 44, 157-165. [CrossRef] [PubMed]

29. Frey, L.; Botan, C.H.; Kreps, G. Investigating Communication: An Introduction to Research Methods, 2nd ed.; Allyn \& Bacon: Boston, MA, USA, 2000. 